\title{
Screening Quality Evaluation Factors of Freeze-Dried Peach (Prunus Persica L. Batsch) Powders from Different Ripening Time Cultivars
}

\author{
Chun-ju Liu, ${ }_{1}^{1}$ Hai-ou Wang, ${ }^{2}$ You-lin Xue, ${ }^{1,3}$ Zhong-yuan Zhang, ${ }^{1}$ Li-ying Niu, ${ }^{1}$ \\ Da-jing Li, ${ }^{1,4}$ Ning Jiang, ${ }^{1}$ Li Cui, ${ }^{1}$ and Chun-quan Liu ${ }^{1}$ \\ ${ }^{1}$ Institute of Farm Product Processing, Jiangsu Academy of Agricultural Sciences, Nanjing 210014, China \\ ${ }^{2}$ School of Food Science, Nanjing Xiaozhuang University, Nanjing 211171, China \\ ${ }^{3}$ College of Light Industry, Liaoning University, Shenyang 110036, China \\ ${ }^{4}$ Jiangsu Key Laboratory for Horticultural Crop Genetic Improvement, Jiangsu Academy of Agricultural Sciences, \\ Nanjing 210014, China \\ Correspondence should be addressed to Da-jing Li; lidajing@163.com
}

Received 24 March 2017; Revised 13 May 2017; Accepted 21 May 2017; Published 27 June 2017

Academic Editor: Ángel Calín-Sánchez

Copyright (c) 2017 Chun-ju Liu et al. This is an open access article distributed under the Creative Commons Attribution License, which permits unrestricted use, distribution, and reproduction in any medium, provided the original work is properly cited.

\begin{abstract}
The quality evaluation of processed products is complex. To simplify the quality evaluation process and improve the efficiency, fourteen evaluation factors of freeze-dried powders of seventeen cultivars of peach at different ripening times were analyzed. The most important evaluation indicators and criteria were obtained by analysis of variance (ANOVA), correlation analysis (CA), principal component analysis (PCA), system cluster analysis (SCA), and analytic hierarchy process (AHP). Results showed that the peach powders had the significant differences in quality $(P<0.05)$, and some processing factors were related with some physicochemical and nutritional factors. Five principle components were extracted by PCA and the cumulative contribution achieved was $84.46 \%$. Through the score plot of the first two principal components, a clear differentiation among ripening times was found and three distinct groups were separated according to ripening time. Five characteristic factors were obtained as titratable acid, browning index, hemicellulose, hygroscopicity, and vitamin C by SCA. Their weights of 0.1249, 0.3007, 0.0514, 0.4916, and 0.0315 were obtained by AHP, respectively. The peach cultivars were divided into four evaluation grades by the comprehensive quality score.
\end{abstract}

\section{Introduction}

Peach (Prunus persica L. Batsch) is the third most abundant fruit worldwide, after the apple and pear. Peach, belonging to the Rosaceae family, has been indigenous to China for over 3000 years and is now cultivated widely in temperate and tropical climates around the world [1]. Peaches are rich in a cultivar of nutrients such as vitamins, minerals, carbohydrates, organic acids, pigments, phenols, antioxidants, and small amounts of proteins and lipids. Peaches are a significant component of the human diet during spring and summer and are often consumed in large quantities [2]. However, peaches are usually highly perishable like other fruits. Drying is one of the most effective techniques for diminishing microbiological activity, reducing water activity of the material, and preventing deterioration [3]. Peach powders obtained after drying can be used in bakery product fillings, fruit sauces, cake mixes, and dairy products [4].

In the drying field, freeze-drying is considered a unique drying process that yields high-quality products, which are widely used in food manufacturing [5]. The produce is frozen below its freezing point and then water is removed from the sample by sublimation of ice to water vapor at pressures below the triple point of water [6]. Freeze-drying technology can produce high-value dried products with good sensory quality and high levels of nutrient retention [7]. Many bioactive substances can be highly preserved during freeze-drying, and their contents are concentrated to improve 
their function and efficacy for disease prevention. Dietary freeze-dried black raspberries have been shown to inhibit the initiation and promotion/progression of chemically induced cancer in rodent esophagus and colon. It also reduced levels of carcinogen-induced DNA damage, reduced growth rate of premalignant cells, and promoted apoptosis [8]. Freezedried strawberry is rich in isothiocyanate and ellagic acid and has been proven to be an effective inhibitor of esophageal tumorigenesis [9]. Usually, moisture contents of fruits are $85-90 \%$, and bioactive substances are concentrated 9-10-fold by freeze-drying [8]. Thus, freeze-dried products can achieve a homologous effect of medicine and food.

Some studies on dried peaches have focused on drying characteristics [10-12]; however, there is no clear information on the evaluation quality of dried peach products. The quality evaluation of peach powder is a complex and difficult task that includes sensory, physicochemical, nutritional, and processing evaluation. Thus, it is important to evaluate the quality of freeze-dried peach powder by a simple method for obtaining the peach powders with higher nutrition, good solubility, taste, and appearance. Many mathematical statistical techniques such as principal component analysis (PCA), system cluster analysis (SCA), and analytic hierarchy process (AHP) have been applied to evaluate the quality difference of fruit and vegetable products $[13,14]$. PCA is a classical method for routine data analysis, which can extract specific information required from large datasets [15]. The dataset is decomposed into a matrix in the form of principal components that can be handled by classical statistical methods, visualized, and interpreted to extract the particular information required [16]. SCA can group many objects into clusters on the basis of similarities within a class and dissimilarities between different clusters. The cluster characteristics are not known in advance but may be determined from the analysis [17]. AHP is applicable to formulate evaluation criteria and it allows quantitative evaluation [18].

In this study, PCA, SCA, and AHP were applied to evaluate the comprehensive quality of different cultivars of freeze-dried peach powders, so as to screen the characteristic factors that affect the quality of dried products and obtain the appropriate cultivars used to process freeze-dried peach powders.

\section{Materials and Methods}

2.1. Material and Sample Preparation. Seventeen cultivars of peach fruit were collected. All peaches were collected during the harvest season (from June to August, 2015) from an orchard located in the Germplasm Resource Center of Peaches (Nanjing, China) and were picked at the same degree of commercial ripeness. These peaches were divided into early-maturing cultivars, mid-maturing cultivars, and latematuring cultivars. Specific information is shown in Table 1. The cultivars of CY1, XH6, VP, CYL, and BRF are rich in total soluble solids, and the total soluble solids content of SS is the lowest. The cultivars of XH6 and CYL are rich in acidity, and the acidity content of FHL is the lowest.

Peaches were cut into $10-\mathrm{mm}$ thick slices after removing the peel and core. The peach slices were quickly placed in freezer trays, frozen at $-30^{\circ} \mathrm{C}$, and freeze-dried with a lyophilizer (Jiangsu Bolaike Frozen Technology Development Co., Ltd., China). The freeze-drying process was conducted at a pressure of $30 \mathrm{~Pa}$ on a heating shelf at $40^{\circ} \mathrm{C}$ for $24 \mathrm{~h}$. After freeze-drying, the products were ground into powders by a milling machine, and the powders were packaged into foil pouches and stored in ultra-low temperature freezer at $-80^{\circ} \mathrm{C}$ for further use.

\subsection{Analytical Methods}

2.2.1. Vitamin $C(\mathrm{mg} / 100 \mathrm{~g})$, Protein $(\mathrm{g} / 100 \mathrm{~g})$, and Titratable Acidity (g/100 g). The protein (Pro), vitamin C (Vc), and titratable acidity (TTA) contents were determined by the Bradford method [19], 2,6-dichloroindophenol titration method [20], and indicator titration method [21], respectively.

2.2.2. Soluble Sugar $(g / 100 g)$. Soluble sugars were extracted according to the method reported by Kim et al. [22] with some modifications. Five grams of peach powder was added to $30 \mathrm{~mL}$ of $80 \%$ ethanol and extracted in a $300 \mathrm{~W}$ ultrasonic water bath at $45^{\circ} \mathrm{C}$ for $60 \mathrm{~min}$. The tubes were centrifuged at $12,000 \times \mathrm{g}$ for $15 \mathrm{~min}$ at $4^{\circ} \mathrm{C}$. The supernatant was transferred to a rotary evaporator flask for evaporating ethanol. Then, $1 \mathrm{~mL}$ of the extracted solution was mixed with an equal volume of acetonitrile and filtered through a $0.45-$ $\mu \mathrm{m}$ membrane filter. The soluble sugars were determined using an HPLC system (Agilent 1200, Palo Alto, CA, USA) equipped with a 1260 refractive index detector. Fructose (Fru), glucose (Glu), and sucrose (Suc) were separated using a Zorbax carbohydrate column $(150 \times 4.6 \mathrm{~mm}, 5 \mu \mathrm{m}$; Agilent Technologies) maintained at $30^{\circ} \mathrm{C}$. The mobile phase was comprised of acetonitrile and water $(75: 25, \mathrm{v} / \mathrm{v})$ at a flow rate of $1 \mathrm{~mL} / \mathrm{min}$.

2.2.3. Water-Soluble Pectin ( $g / 100 \mathrm{~g})$ and Total Pectin $(\mathrm{g} / 100 \mathrm{~g})$. The water-soluble pectin (WSP) and total pectin (TP) were extracted according to the method described by Dong [23] with slight modifications. The peach powders were incubated in ethanol at $85^{\circ} \mathrm{C}$ for $20 \mathrm{~min}$ with agitation on a shaker and were centrifuged at $4,000 \times \mathrm{g}$ for $15 \mathrm{~min}$. The residue was washed with distilled water in a flask for shaking extraction at $50^{\circ} \mathrm{C}$ for $1 \mathrm{~h}$. After centrifugation, the supernatant was collected as WSP and the residue was washed with $80 \mathrm{~mL}$ of $0.5 \mathrm{~mol} / \mathrm{L}$ sulfuric acid and incubated at $80^{\circ} \mathrm{C}$ for $1 \mathrm{~h}$. After centrifugation, the supernatant was used to determine the propectin content. The pectin contents of the above extracts were determined by carbazole colorimetry according to the method of Miyashita and Etoh [24]. The content of TP is the sum of WSP and propectin.

2.2.4. Hemicellulose $(g / 100 g)$ and Cellulose $(g / 100 g)$. The hemicellulose (HCEL) and cellulose (CEL) contents of peach powders were determined by the method described by Dong [23]. The peach powders were hydrolyzed using $3 \%(\mathrm{v} / \mathrm{m})$ sodium dodecyl sulfate at $100^{\circ} \mathrm{C}$ for $1 \mathrm{~h}$ and centrifuged at $4,000 \times \mathrm{g}$ for $15 \mathrm{~min}$. Then, the residue was washed with distilled water for three times and was washed with acetone 


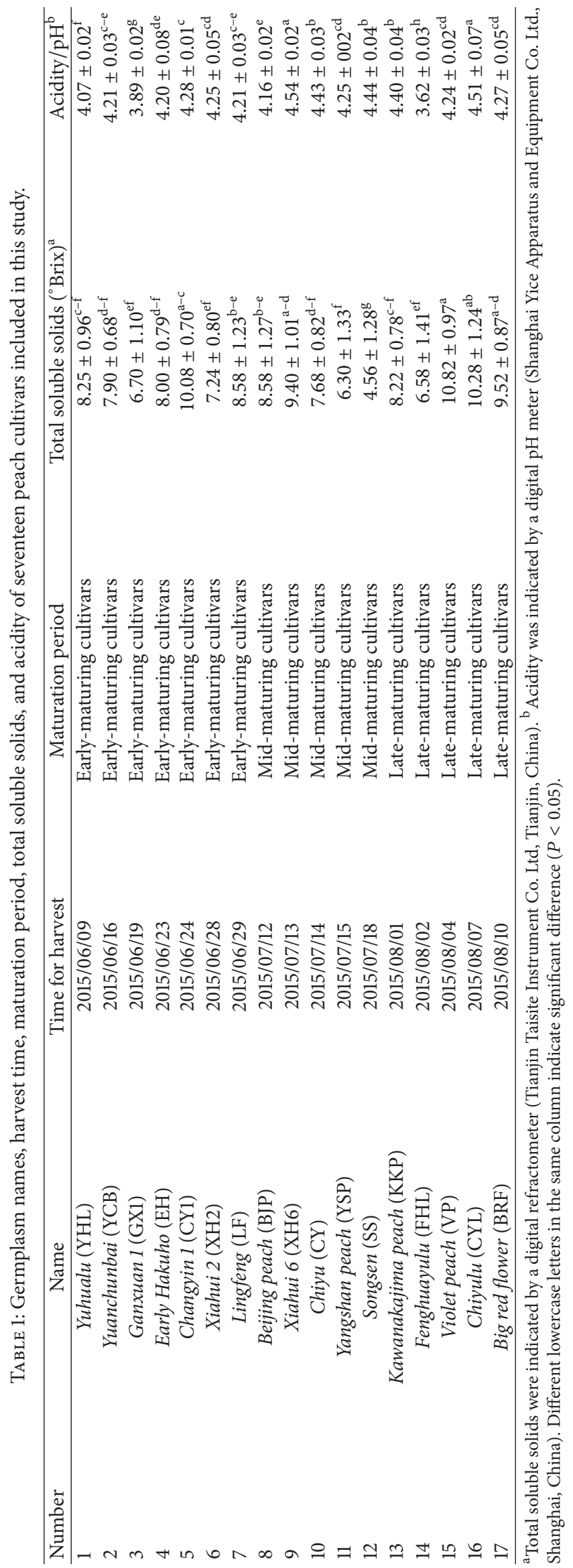


for three times. The retained residue was incubated for $50 \mathrm{~min}$ with $2 \mathrm{~mol} / \mathrm{L}$ hydrochloric acid and rewashed to $\mathrm{pH}$ 6.5-7.0 after centrifugation. The supernatant was collected to determine the HCEL content. The washed residue was hydrolyzed by $5 \mathrm{~mL}$ of $72 \%(\mathrm{v} / \mathrm{v})$ sulfuric acid at $35^{\circ} \mathrm{C}$ for $1 \mathrm{~h}$ and incubated at $100^{\circ} \mathrm{C}$ for $1 \mathrm{~h}$ with $25 \mathrm{~mL}$ of distilled water before filtration. The filtrate was used to determine the CEL content. The CEL and HCEL contents were determined by the phenol-sulfuric acid method [25].

2.2.5. Hygroscopicity (\%). The hygroscopicity (HY) was determined using $1.00 \mathrm{~g}$ of the sample powder stored at room temperature in desiccators containing saturated sodium chloride solutions (75\% relative humidity). The samples were weighed after 1 week, and the HY was expressed in grams of absorbed moisture per $100 \mathrm{~g}$ of dry solids [26].

$$
\mathrm{HY}(\%)=\frac{m_{i}-m_{0}}{m_{0}} \times 100
$$

where $m_{i}$ is the weight of the peach powder after storing for one week $(\mathrm{g})$ and $m_{0}$ is the initial weight of the powder $(\mathrm{g})$.

2.2.6. Hydration Capacity $(\mathrm{g} / \mathrm{g})$. The hydration capacity (HC) of peach powders was determined by the method described by Olayemi et al. [27]. One gram of the powder was placed in a centrifuge tube and $10 \mathrm{~mL}$ of distilled water was gradually added into the tube. The tube was stirred immediately so that the powder fully mixed with water before centrifuging at 3,000 $\times \mathrm{g}$ for $20 \mathrm{~min}$. The supernatant was decanted and the weight of the powder after centrifugation was determined.

$$
\mathrm{HC}=\frac{w_{i}-w_{0}}{w_{0}},
$$

where $w_{i}$ is the weight of the powder after water uptake (g) and $w_{0}$ is the initial weight of the powder $(\mathrm{g})$.

2.2.7. Bulk Density $(g / m L)$. The bulk density (BD) was determined by gently adding $2 \mathrm{~g}$ of peach powder into an empty 10 $\mathrm{mL}$ graduated cylinder and holding the cylinder on a vortex vibrator for $1 \mathrm{~min}$. The ratio of mass $(\mathrm{m})$ of the powder to the volume $(v)$ occupied in the cylinder determines the BD value [28].

$$
\mathrm{BD}=\frac{v}{m}
$$

2.2.8. Browning Index. The browning index (BI) was measured by extracting $1 \mathrm{~g}$ of the powder with $40 \mathrm{~mL}$ of distilled water for $1 \mathrm{~h}$. The mixture was stirred at 5-min intervals before centrifugation at $8000 \times \mathrm{g}$ for $20 \mathrm{~min}$. Absorbance of the supernatant at $420 \mathrm{~nm}$ was recorded [29].

2.3. Statistical Analysis. All experiments were performed in triplicate and the results of one-way analysis of variance (ANOVA) are reported as mean values and standard deviations. Correlations among evaluation factors were assessed by the Pearson test. PCA was applied to determine the principle components of quality evaluation factors, and characteristic quality factors of peach powders were determined by SCA. Finally, the comprehensive quality model was obtained by AHP. Data were processed and analyzed using SPSS 19.0 (IBM, Chicago, USA) and Origin 8.6 (Origin Lab Corp., MA, USA).

\section{Results and Discussion}

3.1. Quality Characters of Freeze-Dried Peach Powder. The quality characteristics of the seventeen freeze-dried peach powders are listed in Tables 2-4. Significant variation in individual indicators among cultivars was identified by ANOVA. The variability is the key to evaluate quality for the selection of the most important factors. Coefficient of variation (CV) of freeze-dried products from the seventeen peach cultivars varied from $10.92 \%$ to $104.69 \%$, indicating that the degree of variation was different. Variability is largely due to genetic differences, which might result in the variation of quality indicators among peach powders [30]. In addition to genetic differences, the variability among peach powder cultivars may also depend on harvest time, climate, geographical environment, and cultivation and management techniques, thus influencing the quality of the dried products [3].

There was significant variation in Vc, TTA, and Pro of the seventeen peach powders $(P<0.05)$, with GX1 having the highest $\mathrm{Vc}$ and FHL showing the highest TTA and Pro (Table 2). The CV of TTA were higher than the other indicators, at $104.69 \%$, implying that the most significant difference among the seventeen peach powders was observed in TTA (Table 2). Based on the results of our study, the Fru, Glu, and Suc content of peach powders ranged from 0.37 (CY) to 1.13 (BRF) g/100 g, from 0.81 (LF) to 2.40 (FHL) g/100 g, and from 1.52 (YSP) to 2.56 (XH6) g/100 g, respectively (Table 2). The soluble sugar content is an interesting parameter because high soluble sugar corresponds to sweetness and aroma and is an important quality indicator for sensory perception of flavor [31].

Considerable differences were found in WSP and TP between early-, mid-, and late-maturing cultivars (Table 3). The WSP and TP content of mid-maturing and late-maturing cultivars were higher than the early-maturing cultivars. The highest WSP and TP contents were found in the fruits of the mid-maturing cultivar CY, and the lowest WSP and TP contents were found in YCB and CY1 of the earlymaturing cultivars, respectively. The coefficients of variation of WSP and TP were higher than those of HCEL and CEL. Furthermore, the HCEL and CEL contents of late-maturing cultivars were greater than those of the early- and midmaturing cultivars except for BRF. There might be more severe lignification for the late-maturing cultivars [32].

Among the processing factors, significant variation was found in $\mathrm{HY}, \mathrm{HC}, \mathrm{BD}$, and BI of the peach powders (Table 4). The HY is an important parameter because high HY would make fruit powder sticky and cause the formation of agglomerates, which makes the power become less physically stable [33]. Freeze-dried peach powders have higher hygroscopic ability owing to the porous structure, which increases the contact area between the hydrophilic groups and the water in air [34]. 
TABle 2: Vitamin C (mg/100 g), titratable acidity (g/100 g), proteins (g/100 g), fructose $(\mathrm{g} / 100 \mathrm{~g})$, glucose $(\mathrm{g} / 100 \mathrm{~g})$, and sucrose $(\mathrm{g} / 100 \mathrm{~g})$ content of peach powders from seventeen varieties.

\begin{tabular}{|c|c|c|c|c|c|c|}
\hline & $\mathrm{Vc}$ & TTA & Pro & Fru & Glu & Suc \\
\hline$\overline{\mathrm{YHL}}$ & $43.14 \pm 0.02^{\mathrm{de} *}$ & $0.24 \pm 0.01^{\mathrm{a}}$ & $0.13 \pm 0.00^{\mathrm{b}}$ & $0.94 \pm 0.05^{\mathrm{d}}$ & $1.07 \pm 0.08^{\mathrm{b}-\mathrm{d}}$ & $1.86 \pm 0.08^{\mathrm{b}}$ \\
\hline YCB & $34.15 \pm 5.87^{\mathrm{d}}$ & $0.20 \pm 0.00^{\mathrm{a}}$ & $0.04 \pm 0.01^{\mathrm{a}}$ & $0.88 \pm 0.00^{\mathrm{d}}$ & $1.34 \pm 0.03^{\mathrm{d}}$ & $2.05 \pm 0.06^{\mathrm{c}}$ \\
\hline GX1 & $81.09 \pm 4.08^{\mathrm{g}}$ & $0.37 \pm 0.01^{\mathrm{a}}$ & $0.29 \pm 0.01^{\mathrm{d}}$ & $0.73 \pm 0.09^{c}$ & $1.00 \pm 0.08^{\mathrm{a}-\mathrm{c}}$ & $1.91 \pm 0.09^{\mathrm{b}}$ \\
\hline $\mathrm{EH}$ & $41.97 \pm 11.25^{\mathrm{de}}$ & $0.23 \pm 0.00^{\mathrm{a}}$ & $0.23 \pm 0.01^{c}$ & $0.64 \pm 0.03^{b c}$ & $0.84 \pm 0.00^{\mathrm{a}}$ & $2.34 \pm 0.08^{\mathrm{e}}$ \\
\hline CY1 & $53.76 \pm 2.74^{\mathrm{f}}$ & $0.23 \pm 0.00^{\mathrm{a}}$ & $0.23 \pm 0.02^{c}$ & $0.56 \pm 0.03^{b}$ & $1.00 \pm 0.02^{\mathrm{a}-\mathrm{c}}$ & $2.24 \pm 0.09^{\mathrm{de}}$ \\
\hline $\mathrm{XH} 2$ & $35.96 \pm 6.79^{\mathrm{d}}$ & $0.28 \pm 0.00^{\mathrm{a}}$ & $0.15 \pm 0.00^{\mathrm{b}}$ & $0.62 \pm 0.07^{b c}$ & $0.83 \pm 0.07^{\mathrm{a}}$ & $1.61 \pm 0.09^{\mathrm{a}}$ \\
\hline $\mathrm{LF}$ & $47.81 \pm 4.28^{\mathrm{ef}}$ & $0.27 \pm 0.01^{\mathrm{a}}$ & $0.29 \pm 0.01^{\mathrm{d}}$ & $0.58 \pm 0.08^{b c}$ & $0.81 \pm 0.07^{\mathrm{a}}$ & $1.85 \pm 0.07^{\mathrm{b}}$ \\
\hline BJP & $55.63 \pm 0.81^{\mathrm{f}}$ & $0.28 \pm 0.00^{\mathrm{a}}$ & $0.35 \pm 0.03^{\mathrm{ef}}$ & $0.86 \pm 0.01^{\mathrm{d}}$ & $0.98 \pm 0.02^{\mathrm{a}-\mathrm{c}}$ & $2.08 \pm 0.08^{c}$ \\
\hline XH6 & $50.07 \pm 1.57^{\mathrm{ef}}$ & $0.19 \pm 0.01^{\mathrm{a}}$ & $0.29 \pm 0.02^{\mathrm{d}}$ & $0.58 \pm 0.08^{b c}$ & $0.84 \pm 0.05^{\mathrm{a}}$ & $2.56 \pm 0.09^{f}$ \\
\hline CY & $42.69 \pm 0.81^{\mathrm{de}}$ & $0.23 \pm 0.01^{\mathrm{a}}$ & $0.31 \pm 0.03^{\mathrm{de}}$ & $0.37 \pm 0.03^{\mathrm{a}}$ & $1.09 \pm 0.11^{\mathrm{cd}}$ & $2.29 \pm 0.06^{\mathrm{de}}$ \\
\hline YSP & $15.52 \pm 3.11^{b c}$ & $2.86 \pm 0.03^{\mathrm{e}}$ & $0.45 \pm 0.00^{\mathrm{h}}$ & $1.00 \pm 0.05^{\mathrm{d}}$ & $0.99 \pm 0.09^{\mathrm{ab}}$ & $1.52 \pm 0.07^{\mathrm{a}}$ \\
\hline SS & $14.74 \pm 1.63^{b c}$ & $2.79 \pm 0.38^{\mathrm{e}}$ & $0.49 \pm 0.03^{\mathrm{i}}$ & $0.89 \pm 0.08^{\mathrm{d}}$ & $0.89 \pm 0.07^{\mathrm{ab}}$ & $1.66 \pm 0.06^{\mathrm{a}}$ \\
\hline KKP & $5.51 \pm 1.54^{\mathrm{ab}}$ & $2.53 \pm 0.04^{\mathrm{d}}$ & $0.36 \pm 0.02^{\mathrm{f}}$ & $0.64 \pm 0.06^{b c}$ & $1.19 \pm 0.09^{\mathrm{d}}$ & $1.54 \pm 0.09^{\mathrm{a}}$ \\
\hline FHL & $21.94 \pm 5.95^{\mathrm{c}}$ & $3.96 \pm 0.02^{f}$ & $0.52 \pm 0.03^{\mathrm{i}}$ & $0.73 \pm 0.08^{\mathfrak{c}}$ & $2.40 \pm 0.09^{f}$ & $1.68 \pm 0.06^{\mathrm{a}}$ \\
\hline VP & $4.37 \pm 0.02^{\mathrm{a}}$ & $2.21 \pm 0.01^{\mathrm{c}}$ & $0.41 \pm 0.01^{\mathrm{g}}$ & $0.95 \pm 0.07^{\mathrm{d}}$ & $1.95 \pm 0.08^{\mathrm{e}}$ & $2.17 \pm 0.05^{\mathrm{cd}}$ \\
\hline CYL & $9.84 \pm 1.54^{\mathrm{ab}}$ & $1.85 \pm 0.05^{\mathrm{b}}$ & $0.36 \pm 0.03^{f}$ & $0.55 \pm 0.08^{\mathrm{b}}$ & $0.98 \pm 0.00^{\mathrm{a}-\mathrm{c}}$ & $1.64 \pm 0.01^{\mathrm{a}}$ \\
\hline BRF & $9.74 \pm 1.55^{\mathrm{ab}}$ & $1.75 \pm 0.02^{\mathrm{b}}$ & $0.34 \pm 0.03^{\mathrm{ef}}$ & $1.13 \pm 0.09^{\mathrm{e}}$ & $1.96 \pm 0.09^{\mathrm{e}}$ & $1.59 \pm 0.07^{\mathrm{a}}$ \\
\hline $\mathrm{SD}$ & 21.60 & 1.26 & 0.13 & 0.20 & 0.47 & 0.32 \\
\hline CV (\%) & 64.66 & 104.69 & 41.22 & 27.11 & 39.35 & 16.76 \\
\hline
\end{tabular}

${ }^{*}$ Values are mean and standard deviation in triplicate. Means for Vc, TTA, Pro, Fru, Glu, and Suc were compared among cultivars using Duncan's multiple comparison test. Different lowercase letters in the same column indicate significant difference $(P<0.05)$. SD represents standard deviation. CV represents coefficient of variation.

TABLE 3: Water-soluble pectin (g/100 g), total pectin (g/100 g), hemicellulose (g/100 g), and cellulose (g/100 g) contents of peach powders from seventeen varieties.

\begin{tabular}{lcccc}
\hline & WSP & TP & HCEL & CEL \\
\hline YHL & $2.51 \pm 0.02^{\mathrm{a} *}$ & $4.15 \pm 0.08^{\mathrm{ab}}$ & $5.96 \pm 0.53^{\mathrm{a}}$ & $0.27 \pm 0.02^{\mathrm{a}-\mathrm{c}}$ \\
YCB & $2.37 \pm 0.60^{\mathrm{a}}$ & $4.50 \pm 0.41^{\mathrm{ab}}$ & $5.92 \pm 0.59^{\mathrm{a}}$ & $0.29 \pm 0.03^{\mathrm{b}-\mathrm{d}}$ \\
GX1 & $2.72 \pm 0.30^{\mathrm{a}}$ & $4.57 \pm 0.09^{\mathrm{ab}}$ & $5.97 \pm 0.07^{\mathrm{a}}$ & $0.30 \pm 0.08^{\mathrm{b}-\mathrm{e}}$ \\
EH & $3.53 \pm 0.30^{\mathrm{a}}$ & $4.81 \pm 0.08^{\mathrm{ab}}$ & $5.70 \pm 0.75^{\mathrm{a}}$ & $0.25 \pm 0.05^{\mathrm{a}-\mathrm{c}}$ \\
CY1 & $2.45 \pm 0.64^{\mathrm{a}}$ & $3.66 \pm 0.07^{\mathrm{a}}$ & $6.81^{\mathrm{a}}$ & $0.19 \pm 0.02^{\mathrm{a}}$ \\
XH2 & $2.78 \pm 0.23^{\mathrm{a}}$ & $5.29 \pm 0.09^{\mathrm{ab}}$ & $7.41 \pm 0.12^{\mathrm{a}}$ & $0.23 \pm 0.01^{\mathrm{ab}}$ \\
LF & $2.82 \pm 0.29^{\mathrm{a}}$ & $4.40 \pm 0.21^{\mathrm{ab}}$ & $7.32 \pm 0.47^{\mathrm{a}}$ & $0.24 \pm 0.01^{\mathrm{a}-\mathrm{c}}$ \\
BJP & $4.44 \pm 0.14^{\mathrm{ab}}$ & $5.94 \pm 0.76^{\mathrm{b}}$ & $5.75 \pm 0.92^{\mathrm{a}}$ & $0.24 \pm 0.01^{\mathrm{a}-\mathrm{c}}$ \\
XH6 & $9.46 \pm 1.92^{\mathrm{c}}$ & $12.06 \pm 0.79^{\mathrm{d}}$ & $6.08 \pm 0.02^{\mathrm{a}}$ & $0.24 \pm 0.01^{\mathrm{a}-\mathrm{c}}$ \\
CY & $14.51 \pm 0.74^{\mathrm{d}}$ & $16.76 \pm 0.21^{\mathrm{e}}$ & $7.35 \pm 0.45^{\mathrm{a}}$ & $0.22 \pm 0.02^{\mathrm{ab}}$ \\
YSP & $9.84 \pm 0.18^{\mathrm{c}}$ & $12.55 \pm 0.07^{\mathrm{d}}$ & $6.73 \pm 1.21^{\mathrm{a}}$ & $0.26 \pm 0.04^{\mathrm{a}-\mathrm{c}}$ \\
SS & $9.05 \pm 1.05^{\mathrm{c}}$ & $12.63 \pm 0.52^{\mathrm{d}}$ & $7.53 \pm 0.00^{\mathrm{a}}$ & $0.32 \pm 0.03^{\mathrm{c}-\mathrm{e}}$ \\
KKP & $13.44 \pm 0.01^{\mathrm{d}}$ & $5.74 \pm 0.01^{\mathrm{a}}$ & $0.35 \pm 0.00^{\mathrm{de}}$ \\
FHL & $10.61 \pm 0.07^{\mathrm{c}}$ & $11.73 \pm 0.34^{\mathrm{d}}$ & $7.22 \pm 1.50^{\mathrm{a}}$ & $0.37 \pm 0.02^{\mathrm{e}}$ \\
VP & $9.24 \pm 0.28^{\mathrm{c}}$ & $12.78 \pm 2.89^{\mathrm{d}}$ & $5.67 \pm 0.52^{\mathrm{a}}$ & $0.35 \pm 0.03^{\mathrm{de}}$ \\
CYL & $8.59 \pm 2.22^{\mathrm{c}}$ & $12.79 \pm 0.47^{\mathrm{d}}$ & 0.79 & $0.36 \pm 0.00^{\mathrm{de}}$ \\
BRF & $5.35 \pm 0.37^{\mathrm{c}}$ & $8.59 \pm 0.15^{\mathrm{c}}$ & 12.00 & $0.22 \pm 0.03^{\mathrm{ab}}$ \\
SD & $5.85 \pm 0.21^{\mathrm{b}}$ & 4.25 & 49.61 & 0.56 \\
CV(\%) & 3.74 & 59.95 & 20.26 \\
\hline V & & 4.25 &
\end{tabular}

${ }^{*}$ Values are mean and standard deviation in triplicate. Means for WSP, TP, HCEL, and CEL were compared among cultivars using Duncan's multiple comparison test. Different lowercase letters in the same column indicate significant difference $(P<0.05)$. SD represents standard deviation. CV represents coefficient of variation. 
TABLE 4: Hygroscopicity (\%), hydration capacity $(\mathrm{g} / \mathrm{g})$, bulk density $(\mathrm{g} / \mathrm{mL})$, and browning index of peach powders from seventeen varieties.

\begin{tabular}{|c|c|c|c|c|}
\hline & $\mathrm{HY}$ & $\mathrm{HC}$ & $\mathrm{BD}$ & BI \\
\hline YHL & $23.39 \pm 0.13^{\mathrm{f}-\mathrm{h} *}$ & $3.11 \pm 0.22^{\mathrm{b}-\mathrm{e}}$ & $0.17 \pm 0.00^{\mathrm{a}}$ & $7.10 \pm 0.14^{\mathrm{f}}$ \\
\hline YCB & $25.98 \pm 1.97^{\mathrm{i}}$ & $2.34 \pm 0.03^{\mathrm{a}-\mathrm{c}}$ & $0.22 \pm 0.00^{\mathrm{d}-\mathrm{f}}$ & $6.78 \pm 0.11^{\mathrm{ef}}$ \\
\hline GX1 & $24.34 \pm 0.20^{\mathrm{h}}$ & $2.39 \pm 0.07^{\mathrm{a}-\mathrm{d}}$ & $0.18 \pm 0.00^{\mathrm{ab}}$ & $5.71 \pm 0.57^{\mathrm{d}}$ \\
\hline $\mathrm{EH}$ & $20.76 \pm 0.21^{\mathrm{b}-\mathrm{d}}$ & $1.68 \pm 1.16^{\mathrm{a}}$ & $0.24 \pm 0.00^{\mathrm{f}-\mathrm{h}}$ & $3.58 \pm 0.64^{b c}$ \\
\hline CY1 & $22.20 \pm 0.37^{\mathrm{d}-\mathrm{g}}$ & $1.94 \pm 0.28^{\mathrm{ab}}$ & $0.21 \pm 0.00^{\mathrm{c}-\mathrm{e}}$ & $2.84 \pm 0.30^{\mathrm{a}}$ \\
\hline $\mathrm{XH} 2$ & $23.73 \pm 0.28^{\mathrm{gh}}$ & $3.60 \pm 1.36^{\mathrm{c}-\mathrm{e}}$ & $0.32 \pm 0.01^{\mathrm{i}}$ & $3.12 \pm 0.26^{\mathrm{ab}}$ \\
\hline LF & $19.72 \pm 0.61^{\mathrm{ab}}$ & $2.93 \pm 0.18^{\mathrm{a}-\mathrm{e}}$ & $0.19 \pm 0.01^{\mathrm{a}-\mathrm{c}}$ & $3.88 \pm 0.02^{c}$ \\
\hline BJP & $24.03 \pm 0.30^{\mathrm{h}}$ & $4.33 \pm 0.07^{\mathrm{e}}$ & $0.32 \pm 0.01^{\mathrm{i}}$ & $5.80 \pm 0.19^{\mathrm{d}}$ \\
\hline XH6 & $20.36 \pm 0.05^{\mathrm{a}-\mathrm{c}}$ & $2.42 \pm 0.17^{\mathrm{a}-\mathrm{d}}$ & $0.20 \pm 0.01^{\mathrm{b}-\mathrm{d}}$ & $2.78 \pm 0.00^{\mathrm{a}}$ \\
\hline $\mathrm{CY}$ & $20.77 \pm 0.24^{\mathrm{b}-\mathrm{d}}$ & $4.01 \pm 0.50^{\mathrm{e}}$ & $0.31 \pm 0.04^{\mathrm{i}}$ & $6.04 \pm 0.04^{\mathrm{de}}$ \\
\hline YSP & $23.10 \pm 0.03^{\mathrm{e}-\mathrm{h}}$ & $3.64 \pm 0.41^{\mathrm{c}-\mathrm{e}}$ & $0.25 \pm 0.00^{\mathrm{gh}}$ & $5.77 \pm 0.05^{\mathrm{d}}$ \\
\hline SS & $29.24 \pm 1.85^{j}$ & $6.57 \pm 0.38^{f}$ & $0.23 \pm 0.00^{\mathrm{e}-\mathrm{g}}$ & $6.46 \pm 0.02^{\mathrm{d}-\mathrm{f}}$ \\
\hline КKР & $21.45 \pm 0.14^{\mathrm{c}-\mathrm{e}}$ & $4.00 \pm 0.26^{\mathrm{e}}$ & $0.32 \pm 0.02^{\mathrm{i}}$ & $5.81 \pm 0.52^{\mathrm{d}}$ \\
\hline FHL & $22.91 \pm 0.07^{\mathrm{e}-\mathrm{h}}$ & $4.15 \pm 0.56^{\mathrm{e}}$ & $0.30 \pm 0.02^{\mathrm{i}}$ & $11.52 \pm 0.47^{\mathrm{h}}$ \\
\hline VP & $21.81 \pm 0.34^{\mathrm{c}-\mathrm{f}}$ & $3.80 \pm 0.51^{\mathrm{de}}$ & $0.26 \pm 0.00^{\mathrm{h}}$ & $8.20 \pm 0.21^{\mathrm{g}}$ \\
\hline CYL & $19.03 \pm 0.11^{\mathrm{a}}$ & $3.68 \pm 0.25^{\mathrm{c}-\mathrm{e}}$ & $0.30 \pm 0.01^{\mathrm{i}}$ & $11.66 \pm 0.37^{h}$ \\
\hline BRF & $22.21 \pm 0.31^{\mathrm{d}-\mathrm{g}}$ & $2.56 \pm 0.03^{\mathrm{a}-\mathrm{d}}$ & $0.31 \pm 0.00^{\mathrm{i}}$ & $6.27 \pm 0.59^{\mathrm{de}}$ \\
\hline SD & 2.47 & 1.17 & 0.54 & 2.60 \\
\hline $\mathrm{CV}(\%)$ & 10.92 & 34.66 & 21.28 & 42.86 \\
\hline
\end{tabular}

${ }^{*}$ Values are mean and standard deviation in triplicate. Means for HY, HC, BD, and BI were compared among cultivars using Duncan's multiple comparison test. Different lowercase letters in the same column indicate significant difference $(P<0.05)$. SD represents standard deviation. CV represents coefficient of variation.

3.2. Correlation Analysis among Quality Factors in FreezeDried Peach Powders. Correlations between physicochemical and processing characteristics of peach powders were analyzed (Table 5). A significant positive relationship was found between Fru and HY $(P<0.05)$. This result indicates that caking and agglomerate formation of peach powder during shelf-life is related to Fru content. Previous studies have also found correlations between HY and Fru in instant milk tea powder [35] and sweet potato slices [36]. Fru is very hygroscopic in that the polar terminals of its molecule can interact strongly with water molecules [37]. Similar to that indicated by $\mathrm{He}$ [35] for milk powder, since monosaccharides (as Fru or Glu) are more hygroscopic than disaccharides, fruit powder should also contain less than $10 \%$ or preferably less than $5 \%$ monosaccharides.

The HC was significantly positively correlated with TTA, WSP, TP, and HCEL $(P<0.05)$ and highly significantly positively correlated with Pro $(P<0.01)$ (Table 5$)$. HC is the water-binding ability of peach powder throughout the drying process, which is related to composition, particle size, $\mathrm{pH}$, fiber porosity, temperature, ionic species, and so on [38]. The HC was correlated with the content and denaturation degree of Pro, which can strongly interact with and adsorb water molecules [39]. Furthermore, pectin is believed to form an independent network, which is beneficial as a water-binding agent. The hydrophilic groups in pectin can interact with polar groups of water molecules to bind many molecules of water $[40,41]$.

The BI was positively correlated with Glu $(P<0.05)$, highly significantly positively correlated with TTA and CEL $(P<0.01)$, and negatively correlated with $\mathrm{Vc}(P<0.05)$
(Table 5). Browning will cause the loss of the original color of fruit powders and customers may experience an unpleasant feeling, which will affect the product sensation and consumer preferences. Nonenzymatic browning was related to the Maillard reaction and ascorbic acid oxidation. Higher Glu could promote the occurrence of the Maillard reaction to increase the degree of browning, and Vc may be involved in ascorbic acid oxidation [42]. Furthermore, TTA might be correlated with ascorbic acid oxidation [43]. So far, there has been no clear relationship between CEL and BI detected. These results revealed important information regarding the relationships among the quality factors, and some factors were indeed overlapped. To screen the important evaluation indicators, it was necessary to further simplify these quality indicators.

3.3. Principal Component Analysis (PCA). The PCA carried out produced five components, which explained $84.46 \%$ of the total variability of the data (Table 6). The first component (42.02\% explaining variance) was positively correlated with TTA, Pro, TP, CEL, HC, and BI. However, Vc was negatively correlated with TTA. The main influencing factors of the second component (15.28\% explaining variance) were Fru and WSP. The factors contributing most to PC3 (11.40\%), PC4 (8.82\%), and PC5 (6.95\%) were principally Glu and HCEL, HY, and BD, respectively. The first and second principal components explaining $57.30 \%$ of the overall variance separated the cultivars into three distinct groups according to the maturing stage, which were named groups 1-3 (Figure 1(a)). Groups 1 and 2 indicated the early- and midmaturing cultivars, which were distinguished through PC2, 


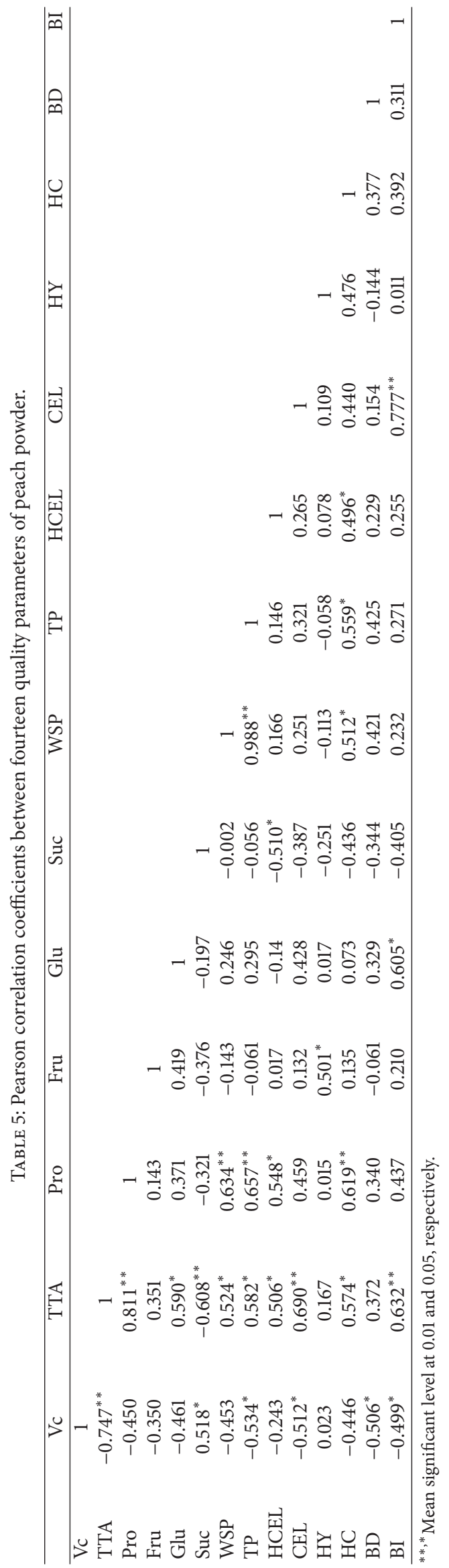


TABLE 6: Varimax factor loadings of the first five principal components.

\begin{tabular}{|c|c|c|c|c|c|}
\hline Quality parameter & PC1 & PC2 & PC3 & PC4 & PC5 \\
\hline $\mathrm{Vc}(\mathrm{mg} / 100 \mathrm{~g})$ & -0.783 & 0.036 & 0.203 & 0.040 & 0.310 \\
\hline TTA (g/100 g) & 0.942 & -0.121 & -0.034 & -0.023 & 0.055 \\
\hline Pro $(g / 100 g)$ & 0.811 & 0.295 & 0.173 & 0.031 & 0.156 \\
\hline Fru (g/100 g) & 0.292 & -0.705 & -0.154 & 0.405 & -0.234 \\
\hline Glu (g/100 g) & 0.556 & -0.167 & -0.697 & 0.143 & -0.040 \\
\hline Suc $(g / 100 g)$ & -0.584 & 0.491 & -0.222 & 0.322 & 0.311 \\
\hline WSP (g/100 g) & 0.647 & 0.663 & 0.043 & 0.311 & -0.012 \\
\hline $\mathrm{TP}(\mathrm{g} / 100 \mathrm{~g})$ & 0.703 & 0.592 & 0.015 & 0.347 & -0.006 \\
\hline HCEL (g/100 g) & 0.493 & -0.088 & 0.622 & -0.442 & 0.038 \\
\hline $\mathrm{CEL}(\mathrm{g} / 100 \mathrm{~g})$ & 0.699 & -0.198 & -0.196 & -0.201 & 0.494 \\
\hline HY (\%) & 0.149 & -0.598 & 0.395 & 0.576 & 0.066 \\
\hline $\mathrm{HC}(\mathrm{g} / \mathrm{g})$ & 0.728 & 0.008 & 0.505 & 0.203 & -0.068 \\
\hline $\mathrm{BD}(\mathrm{g} / \mathrm{mL})$ & 0.543 & 0.280 & -0.065 & -0.214 & -0.586 \\
\hline $\mathrm{BI}$ & 0.705 & -0.213 & -0.350 & -0.266 & 0.312 \\
\hline$\%$ of variance & 42.02 & 15.28 & 11.40 & 8.82 & 6.95 \\
\hline Cumulative\% & 42.02 & 57.30 & 68.70 & 77.51 & 84.46 \\
\hline
\end{tabular}

and groups 2 and 3 (representing the late-maturing cultivars) were discriminated using PC1. The differentiation among maturing stages was found by the plot of score and loading. The correlation between the factors can be seen in the loading plot (Figure 1(b)). The distances between WSP and TP, HCEL and Glu, CEL and BI, and HY and Fru in Figure 1(b) are very close, which indicates that these factors are overlapped. Thus, further classification is needed to obtain the trait factors of each principal component.

3.4. System Cluster Analysis (SCA). To classify the characteristic factors, SCA using Ward's linkage was performed and a dendrogram was obtained on the basis of similarity coefficients.

All cultivars were classified into four major clusters using SCA when the clustering distance was set as 15 based on the similarity among cultivars (Figure 2(a)). Cluster I was composed of CY1, XH6, CY, XH2, EH, LF, YHL, YCB, BJP, and GX1. It contained all of the early-maturing cultivars and parts of the mid-maturing cultivars. The nearness of quality between the early-maturing cultivars and parts of the mid-maturing cultivars may be due to moderate and stable temperature. Cluster II had two mid-maturing cultivars, YSP and SS. The late-maturing cultivars were divided into two parts as cluster III and cluster IV. VP, BRF, and KKP stood in cluster III, and FHL and CYL were included in cluster V.

In terms of similarity or nearness, all of factors could be classified into five major clusters from SCA when the clustering distance was set as 10 (Figure 2(b)). The characteristic factors could be chosen on the basis of the correlations among evaluation factors in each cluster. Cluster I was composed of TTA, Pro, WSP, TP, HC, and BD. The coefficient of variation of TTA was higher than other factors in cluster I (Tables 2-4). In addition, TTA could affect product flavor greatly [44]; thus it was chosen to be one of the characteristic factors. Cluster II had CEL, BI, and Glu, and the largest coefficient variation was BI (Tables 3 and 4). Therefore, BI could be viewed as a representative indicator. Since HCEL stood alone in cluster III, it was sure to be one of the characteristic factors. The coefficient of variation value of Fru was higher than that of HY in cluster IV (Tables 2 and 4). However, measurement of HY was much easier than that of Fru, so HY was chosen as the characteristic factor in cluster IV. In cluster $\mathrm{V}, \mathrm{Vc}$ was regarded as the representative factor due to a higher coefficient of variation value than Suc (Table 2). Thus, five characteristic quality factors of peach powder were finally gained by SCA, which are TTA, BI, HECL, HY, and Vc.

3.5. Analytic Hierarchy Process (AHP). In order to obtain a comprehensive evaluation model, it is necessary to determine the weighting coefficients for each of characteristic quality factors. At first, the original data of five characteristic quality factors should be standardized to eliminate the effects from different dimensions and order of magnitudes of characteristic quality factors (Table 7). Secondly, by comparing two factors to each other, a scale was made to establish the quality evaluation judgment matrix of peach powders. The weights of TTA, BI, HCEL, HY, and Vc were 0.1249, 0.3007, $0.0514,0.4916$, and 0.0315 , respectively. The comprehensive evaluation model was as follows.

$$
\begin{aligned}
Y= & 0.1249 \times x_{1}+0.3007 \times x_{2}+0.0514 \times x_{3}+0.4916 \\
& \times x_{4}+0.0315 \times x_{5},
\end{aligned}
$$

where $x_{1}$ was TTA, $x_{2}$ was BI, $x_{3}$ was HCEL, $x_{4}$ was HY, and $x_{5}$ was $\mathrm{Vc}$.

By the standardized data and the weights of five characteristic quality factors, the synthesis scores and ranking of seventeen peach powders were listed in Table 7. SS had the best comprehensive quality for getting the highest score and ranked number one. XH6 had the worst comprehensive quality for the lowest score.

Based on mean and standard deviation of the synthesis scores of seventeen peach powders, the seventeen cultivars 


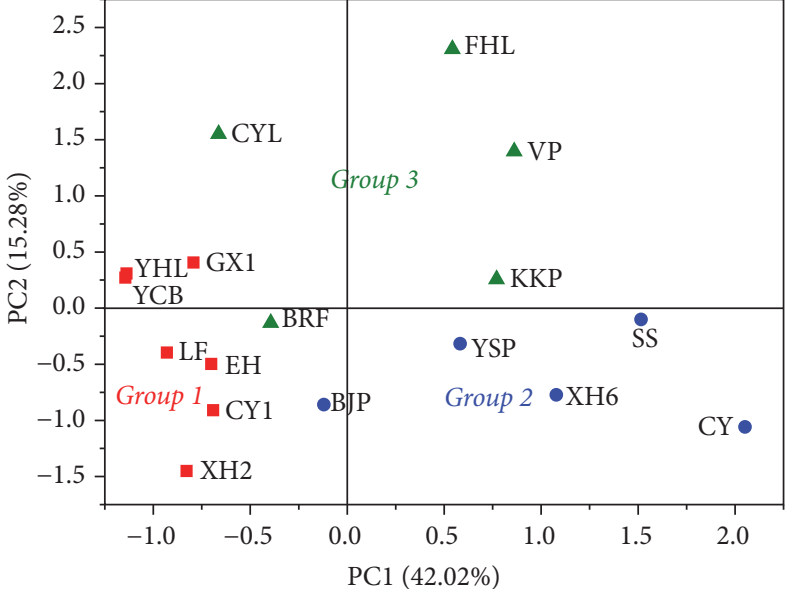

(a)

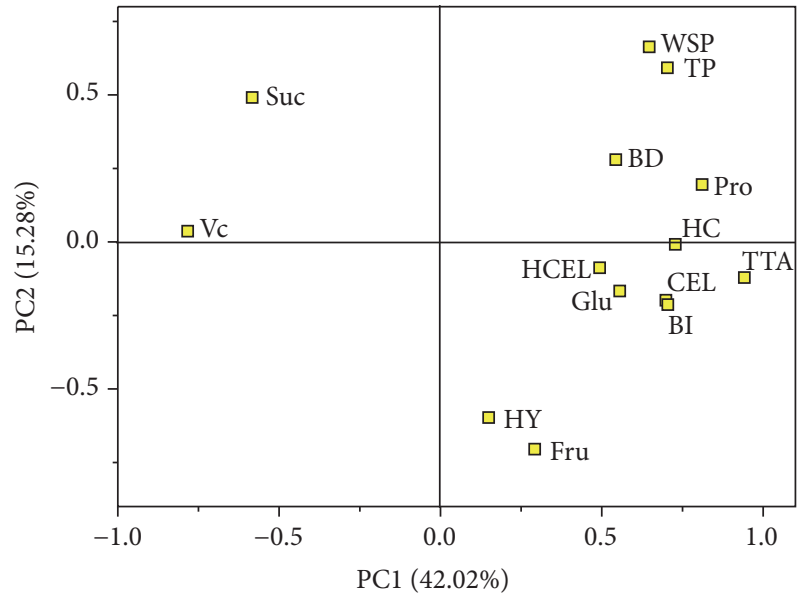

(b)

FIGURE 1: Score (a) and loading (b) plot of the first two components from the PCA analysis of different factors of peach powders. Vc: vitamin C, TTA: titratable acid, Pro: protein, Fru: fructose, Glu: glucose, Suc: sucrose, WSP: water-soluble pectin, TP: total pectin, HCEL: hemicellulose, CEL: cellulose, HY: hygroscopicity, HC: hydration capacity, BD: bulk density, and BI: browning index.

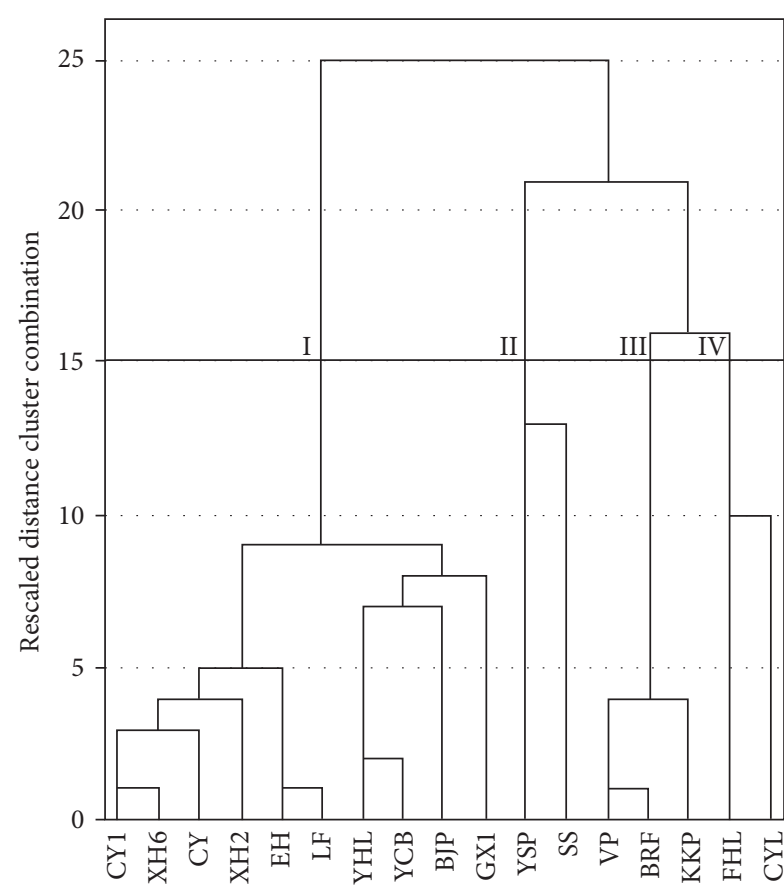

(a)

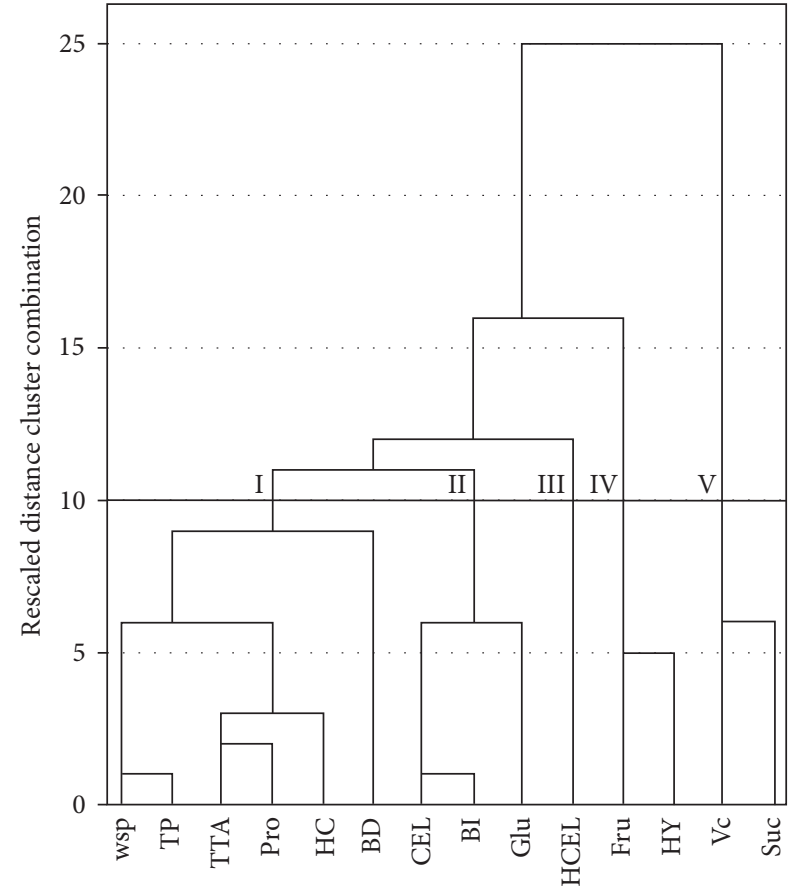

(b)

FIGURE 2: Dendrogram of system cluster analysis of fourteen evaluation factors and seventeen cultivars. Vc: vitamin C, TTA: titratable acid, Pro: protein, Fru: fructose, Glu: glucose, Suc: sucrose, WSP: water-soluble pectin, TP: total pectin, HCEL: hemicellulose, CEL: cellulose, HY: hygroscopicity, HC: hydration capacity, BD: bulk density, and BI: browning index.

were classified into four grades. The comprehensive quality of peach powders were divided into excellent, good, medium, and poor, respectively. The excellent cultivars of freeze-dried peach powders were SS and FHL for the synthesis score greater than or equal to 0.65238 . The good cultivars were $\mathrm{YCB}$, YSP, GX1, BJP, YHL, and VP for the synthesis score within $0 \sim 0.65238$. The medium cultivars were CYL, BRF, KKP, XH2, $\mathrm{CY}$, and CY1 for the synthesis score within $-0.65238 \sim 0$. The poor cultivars were EH, LF, and XH6 for the synthesis score less than or equal to -0.65238 .

\section{Conclusions}

In this study, fourteen evaluation factors of freeze-dried powders of seventeen cultivars of peach at three different ripening times were analyzed by ANOVA, CA, PCA, SCA, 
TABLE 7: The standardized data, scores, and grade of peach powders.

\begin{tabular}{|c|c|c|c|c|c|c|c|c|}
\hline Cultivar & TTA & $\mathrm{BI}$ & HCEL & $\mathrm{HY}$ & Vc & Synthesis score & Ranking & Grade \\
\hline Weight & 0.1249 & 0.3007 & 0.0514 & 0.4916 & 0.0315 & & & \\
\hline SS & 1.2580 & 0.1468 & 0.9653 & 2.6653 & -0.8642 & 1.5339 & 1 & I \\
\hline FHL & 2.1862 & 2.0894 & 1.1891 & 0.1055 & -0.5309 & 0.9975 & 2 & I \\
\hline YCB & -0.7965 & 0.2696 & -0.8466 & 1.3470 & 0.0344 & 0.6014 & 3 & II \\
\hline YSP & 1.3136 & -0.1181 & 2.0742 & 0.1836 & -0.8281 & 0.2993 & 4 & II \\
\hline GX1 & -0.6617 & -0.1411 & -0.7834 & 0.6838 & 2.2075 & 0.2403 & 5 & II \\
\hline BJP & -0.7331 & -0.1066 & 0.9235 & 0.5585 & 1.0288 & 0.2308 & 6 & II \\
\hline YHL & -0.7648 & 0.3923 & -0.7961 & 0.2996 & 0.4506 & 0.1431 & 7 & II \\
\hline VP & 0.7979 & 0.8148 & -1.0742 & -0.3393 & -1.3443 & 0.0804 & 8 & II \\
\hline CYL & 0.5124 & 2.1431 & 0.7971 & -1.4634 & -1.0911 & -0.0045 & 9 & III \\
\hline $\mathrm{BRF}$ & 0.4330 & 0.0739 & -1.1627 & -0.1775 & -1.0957 & -0.1052 & 10 & III \\
\hline KKP & 1.0518 & -0.1028 & 0.1775 & -0.4849 & -1.2916 & -0.1694 & 11 & III \\
\hline $\mathrm{XH} 2$ & -0.7331 & -1.1355 & -0.0880 & 0.4371 & 0.1182 & -0.2188 & 12 & III \\
\hline $\mathrm{CY}$ & -0.7727 & -0.0145 & -0.6443 & -0.7598 & 0.4297 & -0.4940 & 13 & III \\
\hline CY1 & -0.7727 & -1.2430 & -0.8466 & -0.1816 & 0.9422 & -0.5733 & 14 & III \\
\hline $\mathrm{EH}$ & -0.7727 & -0.9589 & 0.1396 & -0.7639 & 0.3964 & -0.7407 & 15 & IV \\
\hline $\mathrm{LF}$ & -0.7410 & -0.8437 & 1.0373 & -1.1844 & 0.6668 & -0.8542 & 16 & IV \\
\hline XH6 & -0.8045 & -1.2660 & -1.0616 & -0.9256 & 0.7714 & -0.9664 & 17 & IV \\
\hline
\end{tabular}

and AHP. ANOVA showed significant differences in the quality of peach powders from different ripening times $(P<$ $0.05)$. Through CA, some physicochemical and nutritional factors were positively or negatively correlated with some processing factors within a certain range. Fourteen evaluation factors were classified into five principle components by PCA. The plot of first and second principal components indicated clear discrimination among cultivars and ripening times. Five characteristic factors were finally obtained by SCA, which were TTA, BI, HCEL, HY, and Vc. The AHP was applied to establish the comprehensive evaluation model and the cultivars were divided into four quality grades for excellent, good, medium, and poor quality. As a result, SS and FHL were selected as two excellent cultivars for the production of freeze-dried peach powders. If the method could be applied to the quality control of produce processing in the food industry, the efficiency of quality evaluation would be greatly improved.

\section{Additional Points}

Practical Application. The quality evaluation procedure of processed food products is a complex and difficult task. In this work, fourteen evaluation factors of freeze-dried powders of seventeen cultivars of peach at three different ripening times were analyzed, such as vitamin C content, titratable acid content, soluble sugar content, hygroscopicity, and browning index. The most important evaluation indicators and criteria were obtained by principal component analysis and system cluster analysis. The comprehensive evaluation model and the evaluation criteria were obtained by analytic hierarchy process. All of these results may provide a scientific basis on evaluating the comprehensive quality of peach powders by determining characteristic factors and analyzing evaluation criteria for simplifying the quality evaluation process and improving its efficiency.

\section{Conflicts of Interest}

The authors declare that they have no conflicts of interest.

\section{Acknowledgments}

This work was supported by the Special Fund for AgroScientific Research in the Public Interest, Ministry of Agriculture (no. 201503142), the National Natural Science Foundation of China (no. 31301592, no. 31201285), the Scientific Research Foundation for the Returned Overseas Chinese Scholars, State Education Ministry of China (no. 2013693), and the General Project of the Education Department of Liaoning Province, China (no. L2014009).

\section{References}

[1] H. Liu, J. Cao, and W. Jiang, "Changes in phenolics and antioxidant property of peach fruit during ripening and responses to 1-methylcyclopropene," Postharvest Biology and Technology, vol. 108, pp. 111-118, 2015.

[2] M. D. C. Fuentes-Pérez, S. Nogales-Delgado, M. C. Ayuso, and D. Bohoyo-Gil, "Different peach cultivars and their suitability for minimal processing," Czech Journal of Food Sciences, vol. 32, no. 5, pp. 413-421, 2014.

[3] J.-F. Bi, X. Wang, Q.-Q. Chen et al., "Evaluation indicators of explosion puffing Fuji apple chips quality from different Chinese origins," LWT - Food Science and Technology, vol. 60, no. 2, pp. 1129-1135, 2015.

[4] I. Doymaz, "Suitability of Thin-Layer Drying Models for Infrared Drying of Peach Slices," Journal of Food Processing and Preservation, vol. 38, no. 6, pp. 2232-2239, 2014. 
[5] H. Jiang, M. Zhang, A. S. Mujumdar, and R.-X. Lim, "Comparison of drying characteristic and uniformity of banana cubes dried by pulse-spouted microwave vacuum drying, freeze drying and microwave freeze drying," Journal of the Science of Food and Agriculture, vol. 94, no. 9, pp. 1827-1834, 2014.

[6] K. Schössler, H. Jäger, and D. Knorr, "Novel contact ultrasound system for the accelerated freeze-drying of vegetables," Innovative Food Science and Emerging Technologies, vol. 16, pp. 113-120, 2012.

[7] F. Pei, Y. Shi, X. Gao et al., "Changes in non-volatile taste components of button mushroom (Agaricus bisporus) during different stages of freeze drying and freeze drying combined with microwave vacuum drying," Food Chemistry, vol. 165, pp. 547-554, 2014.

[8] G. D. Stoner, L.-S. Wang, N. Zikri et al., "Cancer prevention with freeze-dried berries and berry components," Seminars in Cancer Biology, vol. 17, no. 5, pp. 403-410, 2007.

[9] G. D. Stoner, L. A. Kresty, P. S. Carlton, J. C. Siglin, and M. A. Morse, "Isothiocyanates and freeze-dried strawberries as inhibitors of esophageal cancer," Toxicological Sciences, vol. 52, no. 2, pp. 95-100, 1999.

[10] J. Wang and K. Sheng, "Far-infrared and microwave drying of peach," LWT - Food Science and Technology, vol. 39, no. 3, pp. 247-255, 2006.

[11] R. P. Kingsly, R. K. Goyal, M. R. Manikantan, and S. M. Ilyas, "Effects of pretreatments and drying air temperature on drying behaviour of peach slice," International Journal of Food Science \& Technology, vol. 42, no. 1, pp. 65-69, 2007.

[12] A. Zhu and X. Shen, "The model and mass transfer characteristics of convection drying of peach slices," International Journal of Heat and Mass Transfer, vol. 72, pp. 345-351, 2014.

[13] Y. Yang, I. Achaerandio, and M. Pujolà, "Classification of potato cultivars to establish their processing aptitude," Journal of the Science of Food and Agriculture, vol. 96, no. 2, pp. 413-421, 2016.

[14] L. L. Monti, C. A. Bustamante, S. Osorio et al., "Metabolic profiling of a range of peach fruit varieties reveals high metabolic diversity and commonalities and differences during ripening," Food Chemistry, vol. 190, pp. 879-888, 2016.

[15] Z. Chen, H. Wang, C. Ionita, F. Luo, and X. Jiang, "Effects of chicken litter storage time and ammonia content on thermal resistance of desiccation-adapted Salmonella spp.," Applied and Environmental Microbiology, vol. 81, no. 19, pp. 6883-6889, 2015.

[16] E. Finnegan and D. O'Beirne, “Characterising and tracking deterioration patterns of fresh-cut fruit using principal component analysis-Part I," Postharvest Biology and Technology, vol. 100, no. 100, pp. 73-80, 2015.

[17] U. C. Panda, S. K. Sundaray, P. Rath, B. B. Nayak, and D. Bhatta, "Application of factor and cluster analysis for characterization of river and estuarine water systems-A case study: Mahanadi River (India)," Journal of Hydrology, vol. 331, no. 3-4, pp. 434445, 2006.

[18] S. Nikou and J. Mezei, "Evaluation of mobile services and substantial adoption factors with Analytic Hierarchy Process (AHP)," Telecommunications Policy, vol. 37, no. 10, pp. 915-929, 2013.

[19] J. H. Chen, L. Tao, and J. Li, Biochemical experiment, Science Press, Beiing, China, 2003.

[20] AOAC, Vitamin $C$ in vitamin preparations and juices, 2,6dichloroindophenol titrimetric method, Official Methods of Analysis of AOAC International, 1984.
[21] D. S. Sogi, M. Siddiq, and K. D. Dolan, “Total phenolics, carotenoids and antioxidant properties of Tommy Atkin mango cubes as affected by drying techniques," LWT - Food Science and Technology, vol. 62, no. 1, pp. 564-568, 2015.

[22] S. Kim, W. Kim, and I. K. Hwang, "Optimization of the extraction and purification of oligosaccharides from defatted soybean meal," International Journal of Food Science and Technology, vol. 38, no. 3, pp. 337-342, 2003.

[23] T. Dong, "The relationship between the activity of PG and Cx with dietary fibre in sweet orange fruit," Acta Horticulturae Sinica, vol. 34, no. 5, pp. 1287-1292, 2007.

[24] T. Miyashita and H. Etoh, "Improvement of the bitterness and astringency of green tea by sub-critical water extraction," Food Science and Technology Research, vol. 19, no. 3, pp. 471-478, 2013.

[25] A. A. Albalasmeh, A. A. Berhe, and T. A. Ghezzehei, "A new method for rapid determination of carbohydrate and total carbon concentrations using UV spectrophotometry," Carbohydrate Polymers, vol. 97, no. 2, pp. 253-261, 2013.

[26] P. Ibrahim Silva, P. C. Stringheta, R. F. Teófilo, and I. R. N. de Oliveira, "Parameter optimization for spray-drying microencapsulation of jaboticaba (Myrciaria jaboticaba) peel extracts using simultaneous analysis of responses," Journal of Food Engineering, vol. 117, no. 4, pp. 538-544, 2013.

[27] O. Olayemi, A. Oyi, and T. Allagh, "Comparative evaluation of maize, rice and wheat starch powders as pharmaceutical excipients," Nigerian Journal of Pharmaceutical Sciences, vol. 7, no. 1, pp. 131-138, 2008.

[28] A. U. Vanarase, J. G. Osorio, and F. J. Muzzio, "Effects of powder flow properties and shear environment on the performance of continuous mixing of pharmaceutical powders," Powder Technology, vol. 246, pp. 63-72, 2013.

[29] H.-S. Chung and J. H. Lee, "Comparative evaluation of physicochemical properties of pine needle powders prepared by different drying methods," Preventive Nutrition and Food Science, vol. 20, no. 2, pp. 143-147, 2015.

[30] D. Jacopo, B. Francesca, D. V. Lucia et al., "Physico-chemical characteristics of thermally processed purée from different strawberry genotypes," Journal of Food Composition and Analysis, vol. 43, pp. 106-118, 2015.

[31] M. Colaric, R. Veberic, F. Stampar, and M. Hudina, "Evaluation of peach and nectarine fruit quality and correlations between sensory and chemical attributes," Journal of the Science of Food and Agriculture, vol. 85, no. 15, pp. 2611-2616, 2005.

[32] L. L. Shan, X. Li, P. Wang et al., "Characterization of cDNAs associated with lignification and their expression profiles in loquat fruit with different lignin accumulation," Planta, vol. 227, no. 6, pp. 1243-1254, 2008.

[33] M. Cano-Chauca, P. C. Stringheta, A. M. Ramos, and J. CalVidal, "Effect of the carriers on the microstructure of mango powder obtained by spray drying and its functional characterization," Innovative Food Science and Emerging Technologies, vol. 6, no. 4, pp. 420-428, 2005.

[34] S. Liliana, P. V. Diana, and A. A. Alfredo, "Structural, physical, functional and nutraceutical changes of freeze-dried fruit," African Journal of Biotechnology, vol. 14, no. 6, pp. 442-450, 2015.

[35] J. He, "Powdered composition for use in an instant milk tea powder. U.S," Patent Application, vol. 14, no. 785, p. 669, 2014.

[36] J. Junqueira, K. Mendonça, and J. Corrêa, "Microwave drying of sweet potato (Ipomoea batatas (L.)) slices: Influence of the osmotic pretreatment," Defect and Diffusion Forum, vol. 367, pp. 167-174, 2016. 
[37] S. Jaya and H. Das, "Effect of maltodextrin, glycerol monostearate and tricalcium phosphate on vacuum dried mango powder properties," Journal of Food Engineering, vol. 63, no. 2, pp. 125-134, 2004.

[38] H. Chen, Z. Qu, L. Fu, P. Dong, and X. Zhang, "Studies on functional properties of water insoluble polysaccharides with different particle size prepared from the tea," China Food Additives, vol. 11, no. 11, pp. 593-606, 2012.

[39] R. Osen, S. Toelstede, F. Wild, P. Eisner, and U. SchweiggertWeisz, "High moisture extrusion cooking of pea protein isolates: Raw material characteristics, extruder responses, and texture properties," Journal of Food Engineering, vol. 127, pp. 67-74, 2014.

[40] M. Szymanska-Chargot and A. Zdunek, "Use of FT-IR Spectra and PCA to the Bulk Characterization of Cell Wall Residues of Fruits and Vegetables Along a Fraction Process," Food Biophysics, vol. 8, no. 1, pp. 29-42, 2013.

[41] U. Einhorn-Stoll, H. Hatakeyama, and T. Hatakeyama, "Influence of pectin modification on water binding properties," Food Hydrocolloids, vol. 27, no. 2, pp. 494-502, 2012.

[42] Y. Wu, J. H. Qi, M. Q. Huang, C. Ding, Y. Shi, and P. Liu, "Analysis of substrates and products of non-enzymatic browning in chinese chestnut," Chinese Agricultural Science Bulletin, vol. 28, no. 30, pp. 267-271, 2012.

[43] E. Pelizzetti, E. Mentasti, and E. Pramauro, "Kinetics and mechanism of the oxidation of ascorbic acid by tris $(1,10$ phenanthroline)iron(III) and its derivatives in aqueous acidic perchlorate media," Inorganic Chemistry, vol. 15, no. 11, pp. 2898-2900, 1976.

[44] J. Y. Nie, Analytical techniques of fruit quality and safety, Chemical Industry Press, Beijing, China, 2009. 

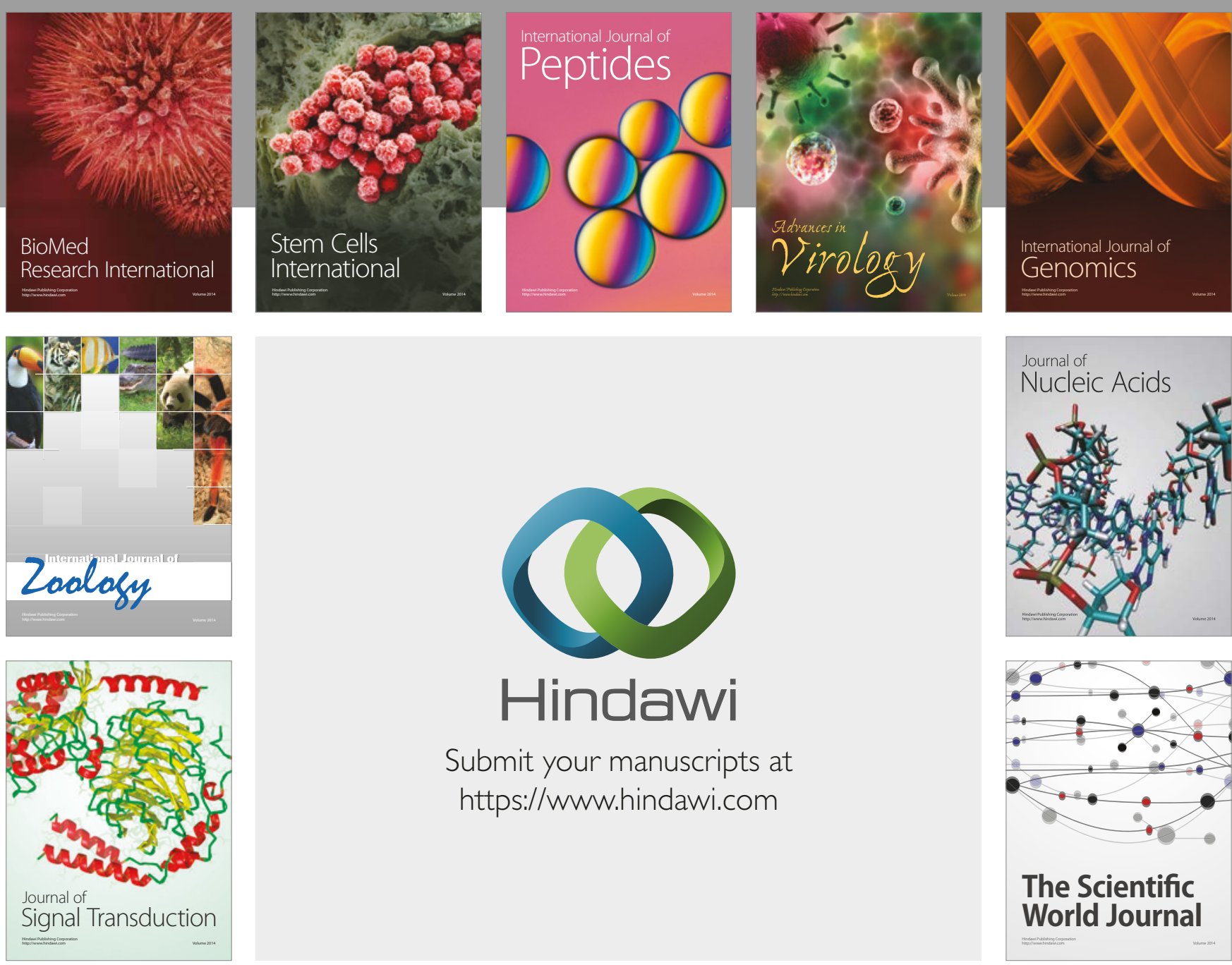

Submit your manuscripts at

https://www.hindawi.com
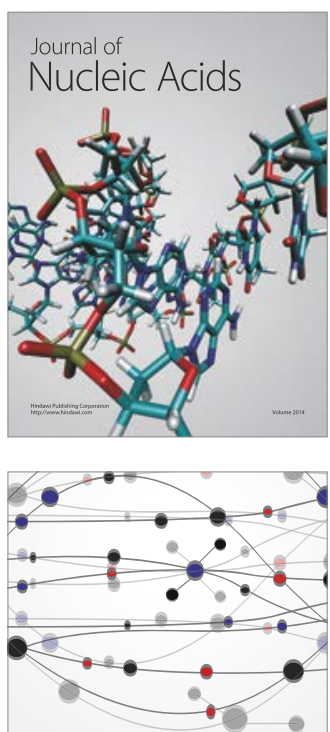

The Scientific World Journal

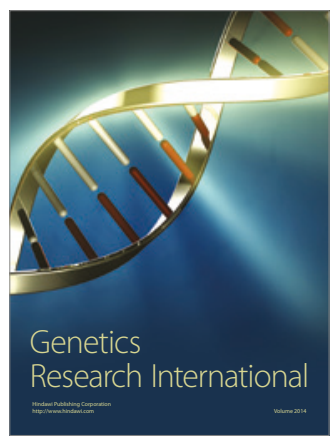

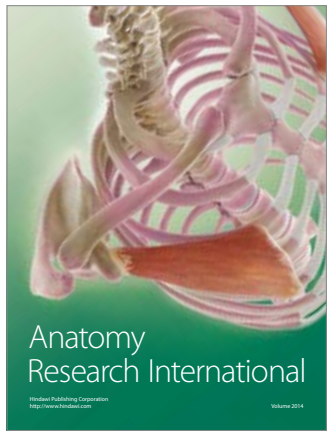

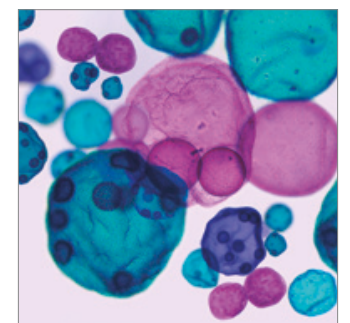

International Journal of Microbiology
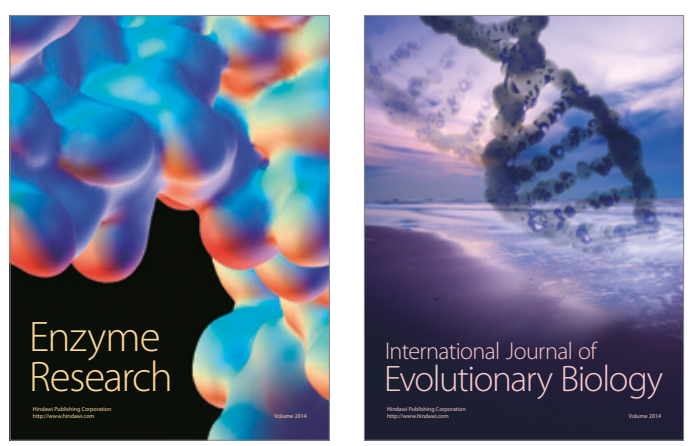
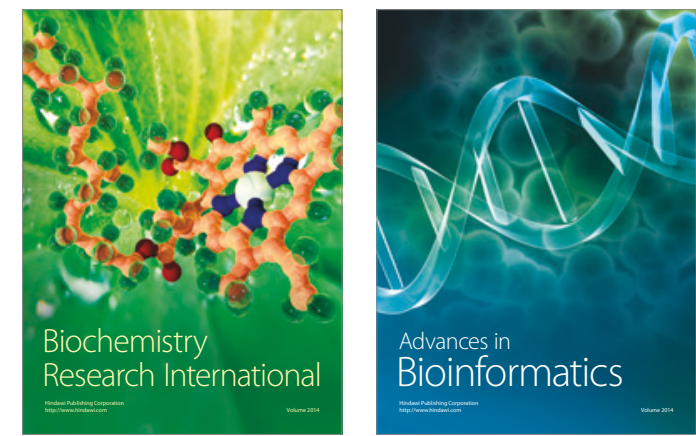

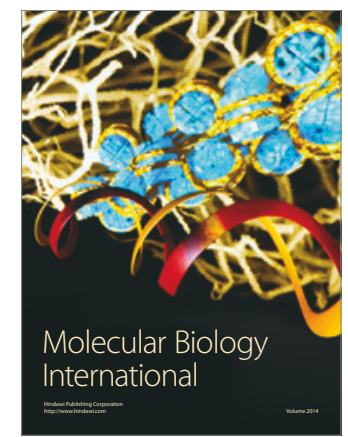

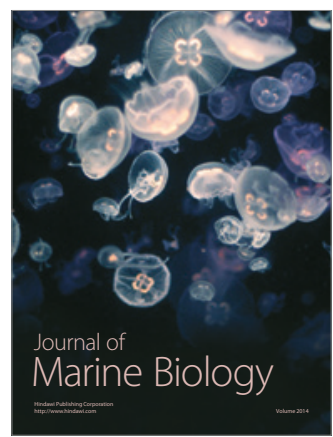

